\title{
A arte como profissão e trabalho: Pierre-Michel Menger e a sociologia das artes
}

Vera Borges

\section{(2) OpenEdition \\ Journals}

Edição electrónica

URL: http://journals.openedition.org/rccs/1209

DOI: $10.4000 /$ rccs. 1209

ISSN: 2182-7435

Editora

Centro de Estudos Sociais da Universidade de Coimbra

\section{Edição impressa}

Data de publição: 1 dezembro 2003

Paginação: 129-134

ISSN: 0254-1106

\section{Refêrencia eletrónica}

Vera Borges, «A arte como profissão e trabalho: Pierre-Michel Menger e a sociologia das artes », Revista Crítica de Ciências Sociais [Online], 67 | 2003, posto online no dia 01 outubro 2012, consultado o 21 setembro 2020. URL : http://journals.openedition.org/rccs/1209 ; DOI : https://doi.org/10.4000/ rccs. 1209 


\section{Revisões Críticas}

\section{A arte como profissão e trabalho: Pierre-Michel Menger e a sociologia das artes}

O aparecimento do mais recente livro de Pierre-Michel Menger, Portrait de l'artiste en travailleur, constitui uma oportunidade ímpar para reflectirmos sobre os caminhos da sociologia das artes, ancorados nos trabalhos de investigação desse sociólogo.

Vinte anos depois da primeira edição de Le paradoxe du musicien, obra que marca o princípio do seu percurso, profundamente ligado à sociologia da criação musical, o autor edifica um importante e incontornável quadro conceptual, no domínio da sociologia das profissões, mercados das artes e trabalho artístico. ${ }^{1}$

No princípio dos anos noventa, Pierre-Michel Menger sucedeu a Raymonde Moulin na direcção do Centro de Sociologia das Artes e, desde então, tem vindo a dedicar-se, em particular, ao estudo dos diferentes métiers do espectáculo, modalidades de carreira dos artistas, mercados de trabalho nas artes, impacto das políticas culturais públicas. ${ }^{2}$

Dois dos seus livros mais recentes testemunham, claramente, a organização do seu campo de pesquisas.

Em primeiro lugar, destaca-se a análise da arte como profissão: o livro La profession de comédien. Formations, activités et carrières dans la démultiplication de soi $(\mathrm{Pa}-$ ris, La Documentation Française, 1997, 455 pp.) é disso um exemplo e representa um domínio de aplicação das démarches teóricas que Pierre-Michel Menger preconiza para as artes do espectáculo.

Em segundo lugar, a análise da arte como trabalho: o livro Portrait de l'artiste en travailleur. Métamorphoses du capitalisme (Paris, Seuil, 2002, 96 pp.) apresenta a arte como um modelo fecundo para o estudo das formas contemporâneas de emprego, recomposição dos mercados de trabalho e gestão das carreiras.

Em conjunto, estes livros merecem-nos duas breves notas, relevantes para a sua leitura. Por um lado, o autor concebe uma aproximação sociológica das artes atenta à situação do artista, à sua aprendizagem e gestão da incerteza e do risco, às suas condições de profissionalização, produção das obras e acumulação de saberes, no seio das organizações artísticas. Por outro lado, o autor procura nos instrumentos de trabalho de outras disciplinas, como a história da arte e a economia, uma resposta pluridisciplinar para o estudo dos mundos da arte, inovação e originalidade.

\footnotetext{
${ }^{1}$ Cf. P.-M. Menger, Le paradoxe du musicien. Le compositeur, le mélomane et l'État dans la société contemporaine, Paris, Flammarion, 1983. O autor publicou outros trabalhos dedicados à sociologia da produção e do consumo musical: La condition du compositeur et le marché de la musique contemporaine en France, Paris, La Documentation Française, 1979; Les laboratoires de la création musicale, Paris, La Documentation Française, 1989. Do mesmo autor, outras contribuições interessantes para o estudo do mundo da música: "L'oreille spéculative", Revue Française de Sociologie, número especial "Sociologie de l'art et de la littérature" (sob a direcção de J.-C. Chamboredon e P.-M Menger), XXVII (3), Julho-Setembro, 1986, pp. 445-479; "Technological innovations in contemporary music. A socio-economic view”, Journal of the Royal Musical Association, vol. 114, Belfast, 1989, pp. 92-101; “L’Opéra, bien public?”, Esprit, Março-Abril, 1989, pp. 88-96.

2 Actualmente, o Centro de Sociologia das Artes designa-se Centro de Sociologia do Trabalho e das Artes, unidade de investigação da École des Hautes Études en Sciences Sociales, criada em 1983.
} 
1. A arte como profissão: a incerteza e o risco

Ao longo do seu percurso de investigação, Pierre-Michel Menger tem privilegiado o estudo das profissões e mercados artísticos, organizações e políticas da arte e da cultura.

$\mathrm{O}$ resultado mais recente deste programa de pesquisas foi a publicação de La profession de comédien, um livro de referência pela estratégia metodológica utilizada, categorias de análise escolhidas, alcance dos resultados e inúmeros pontos de interesse para o estudo dos mundos artísticos.

Este amplo e rigoroso trabalho apoia-se na análise dos dados do primeiro grande inquérito realizado junto de um milhar de actores e tem como objectivo principal estudar a identidade e a actividade deste grupo profissional, em França. ${ }^{3}$

A estrutura do livro assenta na descrição da profissão do actor face às outras profissões artísticas, na análise das trajectórias de formação e aprendizagem profissional dos actores, o seu emprego e trabalho nos diferentes sectores de actividade, o exercício da profissão e o funcionamento das organizações artísticas.

De acordo com Pierre-Michel Menger, a forte progressão do número de efectivos e o aumento da sua taxa de desemprego são duas importantes características da evolução demográfica dos actores, visíveis pela análise das diferentes categorias de artistas, consideradas no recenseamento da população, realizado pelo INSEE. ${ }^{4}$

$\mathrm{O}$ autor descreve assim um métier no qual a incerteza, o risco e a concorrência interindividual representam constrangimentos fortes, no princípio e no decurso da carreira dos actores, mas geram também um certo encantamento e magia, capazes de seduzir os mais jovens. ${ }^{5}$

Os contornos actuais do mercado de trabalho dos actores confinam, à partida, mais candidatos a uma carreira artística com percursos muito enriquecidos, uma profissionalização crescente (alcançável em vários sectores de actividade) e, ainda, uma capacidade de resposta cada vez mais alargada por parte destes profissionais.

Sem barreiras fortes de selecção, sem a exigência de uma formação técnica longa, sem disposições estatutárias que regulamentem o exercício da profissão, entrar é fácil, manter-se é o grande desafio para os actores.

$\mathrm{Na}$ primeira fase de selecção, as competências requeridas para o exercício deste métier são a originalidade, a expressividade, a iniciativa e o talento demonstrados. Acima dos pré-requisitos técnicos iniciais, indispensáveis para um músico clássico, encontram-se as disposições que o actor manifesta e que determinam a sua escolha. No entanto, a formação dos actores é um passo muito importante para a sua socialização e integração no meio profissional. Estas são, aliás, etapas que Pierre-Michel Menger considera solidárias, no decurso da carreira do actor, pois a aprendizagem no palco coexiste com o próprio exercício da profissão.

Os actores que resistem no mercado de trabalho durante mais tempo são considerados talentosos e a sua reputação tende a consolidar-se. A combinação do talento com a capacidade de se relacionar com os

\footnotetext{
${ }^{3}$ No passado, as pesquisas francesas consagradas a esta profissão foram da responsabilidade de Jean Duvignaud (L'acteur, Paris, Gallimard, 1965 e Sociologie du théâtre, Paris, PUF, 1965). Mais recentemente, uma equipa dirigida por Catherine Paradeise divulgou os resultados de um trabalho realizado junto de cem actores (Les comédiens. Profession et marchés du travail, Paris, PUF, 1998).

${ }^{4}$ Institut National de la Statistique et des Études Économiques, em França.

${ }^{5} \mathrm{O}$ autor apresentou e discutiu estes enunciados na conferência intitulada $Y$ a-t-il trop d'artistes? Controverses sociologiques et économiques, realizada na Universidade Nova de Lisboa, em 2001.
} 
colegas, com as diferentes equipas de trabalho e com os responsáveis é uma condição de permanência e de reconhecimento profissional no mundo artístico.

Por essa razão, os actores principiantes e experientes mantêm-se associados a redes de relações com diversos intervenientes nos processos de produção artística. Estas redes profissionais, sempre ligadas ao mercado de trabalho, permitem-lhes ter um acesso rápido e imediato às informações sobre os papéis, os castings, as audições, os projectos, os espectáculos, os filmes, enfim, os empregos disponíveis.

Para compreendermos como se organizam, afinal, as actuais trajectórias profissionais dos actores, Pierre-Michel Menger descreve a diversidade e as incertezas que caracterizam as suas carreiras individuais, assinalando a acumulação de funções e a diversificação dos sectores de actividade onde trabalham.

Ser actor é trabalhar no teatro, na televisão e no cinema, acumular funções e actividades profissionais diversificadas. $\mathrm{O}$ autor associa a esta "desmultiplicação de si", mecanismos como a mobilidade sectorial e a polivalência profissional dos actores (p. 132). E acrescenta ainda: a acumulação de experiências e contratos de trabalho - com diferentes mestres, nas várias estruturas artísticas e sectores de actividade é decisiva para a inserção e integração dos actores no mercado.

Estamos assim em condições de perguntar: de acordo com os resultados das pesquisas de Pierre-Michel Menger, qual é o tipo de contrato de trabalho predominante no mundo das artes? Face à preca- riedade e incerteza das profissões artísticas, como explica o autor a insistência na profissão de actor, cujas gratificações monetárias podem tardar ou nunca acontecer, e ainda, as fortes desigualdades dos rendimentos auferidos?

Em França, a actividade dos actores no cinema, audiovisual e espectáculo ao vivo divide-se entre os empregos assalariados permanentes, no interior das organizações artísticas estáveis, os empregos independentes remunerados e os contratos de emprego intermitente que conferem aos artistas um estatuto próximo dos independentes.

O elevado recurso ao assalariado intermitente nas artes resulta, segundo o autor, de um conjunto de factores interligados, como a organização empresarial do sector artístico, as políticas de intervenção no sector cultural, a multiplicação de estruturas e contratos por projecto, o volume crescente de trabalho artístico e técnico no sector audiovisual, as transformações do próprio mercado de emprego.

Não é a primeira vez que Pierre-Michel Menger se debruça sobre o funcionamento do regime de trabalho intermitente francês, único na Europa. Já o fizera noutras ocasiões, apontando as principais características da forma dominante de emprego dos artistas: o assalariado intermitente com uma multiplicidade de entidades empregadoras, uma certa autonomia do artista, as relações de trabalho temporárias, a diversificação dos riscos profissionais, a luta contra a precariedade e o risco da profissão. ${ }^{6}$

Actualmente, em França, o contrato de duração determinada (CDD) intermitente

\footnotetext{
${ }^{6}$ Cf. os estudos teóricos e empíricos do autor que antecederam este livro, em particular: "Rationalité et incertitude de la vie d'artiste", L'Année sociologique, vol. 39, 1989, pp. 111-151; "Marché du travail artistique et socialisation du risque: le cas des arts du spectacle", Revue Française de Sociologie, XXXII (1), 1991, pp. 61-74 ; "Être artiste par intermittence. La flexibilité du travail et le risque professionnel dans les arts du spectacle”, Travail et Emploi, n 60, 1994, pp. 4-22. E ainda: P.-M. Menger e M. Gurgand, "Work and compensated unemployment in the performing arts. Exogenous and endogenous uncertainty in artistic labour markets", in V. Ginsburgh e P-M. Menger (dir.), Economics of the arts, Amesterdão, North Holland, 1996, pp. 347-381.
} 
e a indemnização prevista para os períodos de não trabalho representam o regime da maioria dos artistas e de um número considerável de técnicos. Inicialmente criado para o sector do cinema, o regime de indemnização específico para os períodos de não trabalho dos artistas e técnicos alargou-se às outras actividades ligadas ao espectáculo.

Neste livro, Pierre-Michel Menger confirma que o referido sistema contribuiu para o aumento do número de actores, mas sublinha que para a escolha destas profissões contribuem muito significativamente as recompensas resultantes da natureza e variedade das tarefas e actividades artísticas, autonomia dos indivíduos, aprendizagem incessante do "eu", reconhecimento do mérito individual, prestígio social e estatuto. Além disso, os artistas reconhecidos, com sucesso e elevados rendimentos, continuam a alimentar o sonho de que tudo pode acontecer. O sucesso é imprevisível e não existe uma relação evidente entre este e as características sociais ou a formação artística dos indivíduos.

O autor considera que a situação dos artistas, como descrita acima, insere-se num "regime de emprego hiper-flexível" (p. 134), na medida em que os artistas e os técnicos, ligados ao métier do espectáculo, trabalham durante períodos de curta duração e não trabalham durante períodos de tempo mais ou menos longos, mantendo-se disponíveis e assegurando a flexibilidade da produção artística.

Esta hiper-flexibilidade do regime de emprego nas artes é produtiva para a análise de outros grupos profissionais, o que demonstra também que os sistemas de tra- balho alternativos ao "assalariado à antiga" aproximam as profissões artísticas das outras profissões. Lembramos o caso dos jovens diplomados: por exemplo, os jovens advogados e o trabalho muitas vezes não remunerado nos escritórios, situação que se mantém devido à existência de um elevado número de profissionais disponíveis no mercado de trabalho.

É neste sentido que, tendo como ponto de partida as questões levantadas no domínio das artes do espectáculo, Pierre-Michel Menger explora abertamente a evolução dos mercados contemporâneos do trabalho, registando a evolução específica dos mercados contemporâneos artísticos.

A propósito das actuais configurações dos mercados artísticos, sublinhamos a importância de uma obra recente co-dirigida pelo autor: Le spectacle vivant. Neste livro, os sectores de actividade como o teatro, a dança, a música, entre outros, são analisados à luz da estruturação do seu campo profissional, lógicas de produção e difusão dos espectáculos, o seu impacto nas lógicas e práticas de emprego e gestão dos recursos humanos, nas diferentes estruturas do espectáculo. ${ }^{7}$

A generalização das hipóteses lançadas pelo autor, no livro La profession de comédien e nos trabalhos que tem vindo a desenvolver, ao longo dos anos, tornaram possível a elaboração de um modelo de análise das artes fecundo e indissociável do carácter pluridisciplinar da sua investigação. Como veremos a seguir, a construção deste modelo passa pelo exame das teorias e dos métodos de análise sociológica e económica, ligados ao trabalho, à gestão dos riscos e das incertezas profissionais. ${ }^{8}$

\footnotetext{
7 Cf. P.-M. Menger, Rémi Debeauvais e François Piettre (dir.), Le spectacle vivant, Paris, La Documentation Française, 1997 ; P.-M. Menger, "Les intermittents du spectacle: croissance de l'emploi et croissance du chômage indemnisé”, Insee Première, Fevereiro, 1997, 4 p.

${ }^{8}$ Daqui resultaram a coordenação de um número especial da Revue Française de Sociologie, "Sociologie et économie", 1997, e os trabalhos que consagrou a esta temática, em obras colectivas, seminários e colóquios, nos últimos dez anos.
} 
2. A arte como trabalho: a inovação $e$ a originalidade

O livro Portrait de l'artiste en travailleur representa o momento de articulação dos principais domínios em que se apoia a investigação de Pierre-Michel Menger. Revela-se ainda um importante passo para o seu percurso pessoal e para os desafios que se impõem hoje à sociologia das artes. Como o próprio nome indica, este livro é uma análise sociológica da arte e do artista, realizada a partir da categoria conceptual trabalho. Mas como e porquê uma análise da arte construída nestes termos?

Nas obras e artigos publicados, nos seminários que dirige, o autor defende que os estudos sociológicos das artes e das profissões artísticas devem incidir sobre o que faz a sua especificidade, o que as distingue e o que as aproxima das outras formas de trabalho, a importância da inovação, da originalidade, da competência profissional para a renovação de cada domínio artístico e para a análise de outros mundos produtivos.

Além disso, a diferenciação das actividades e domínios artísticos é muito grande e a categoria trabalho permitirá evidenciar as suas diferenças e as suas similitudes. Cada mundo artístico coloca à prova empírica os paradigmas da sociologia e origina investigações muito diversas, de acordo com o enfoque da pesquisa: a organização artística, o recrutamento e a formação, o mercado de trabalho, o consumo das obras. Mais ainda: fazer uma análise das artes, seguindo a linha de investigação sugerida, consiste em explorar o processo de criação como um trabalho. Cada vez mais, os próprios artistas representam esse processo e abrem os seus espaços de criação, os seus ateliers, as suas salas de ensaio, aos investigadores e ao público em geral.

A questão principal que está na origem de Portrait de l'artiste en travailleur é a se- guinte: ao falar da actividade de criação estaremos a falar de um trabalho cujos modos de organização económica e social servem como instrumentos de leitura de outros mundos produtivos? Ou, pelo contrário, as particularidades dos mundos artísticos obrigam-nos a construir uma aproximação oposta à anterior?

Para ultrapassar este dilema, o autor propõe-nos seguir as actividades de criação artística "[...] como a expressão mais avançada dos novos modos de produção e das novas relações de emprego engendradas pelas mutações recentes do capitalismo. Longe das representações românticas $[\ldots]$ seria agora necessário olhar para o criador como uma figura exemplar do novo trabalhador [...]. Nas representações actuais, o artista é quase como uma incarnação possível do trabalhador do futuro, é quase como a figura do profissional inventivo, móvel, rebelde perante as hierarquias, intrinsecamente motivado, que vive numa economia da incerteza, e mais exposto aos riscos de concorrência inter-individual e às novas inseguranças das trajectórias profissionais" (pp. 8 e 9).

Como tivemos oportunidade de comprovar acima, a amplitude e a riqueza dos resultados dos trabalhos empíricos, realizados pelo autor e pela equipa que dirige, permitem-lhe testar, neste livro, as inúmeras hipóteses de análise, no que respeita às novas configurações, quer da actividade profissional artística, quer de outros sectores de actividade.

O autor demonstra que a procura permanente de originalidade e de novidade na concepção e produção artísticas tem por si mesma consequências originais, quer no funcionamento do mercado de emprego artístico, quer nas formas organizacionais da actividade produtiva em geral. É aqui que reside a força deste livro e será este o mote das três partes que, solidamente construídas, o compõem. 
Na primeira parte, Pierre-Michel Menger questiona até que ponto as artes constituem ainda um domínio cujos princípios de funcionamento não são comparáveis aos vulgares mundos de produção ou até que ponto as artes obedecem às mesmas regras económicas, com os devidos ajustamentos.

$\mathrm{Na}$ reflexão que promove em torno desta temática, o autor avalia um importante conjunto de posições teóricas que lhe permitem construir este novo "retrato do artista”. A saber, autores tão diferentes como Adam Smith, Karl Marx, Theodor Adorno, Daniel Bell, Arthur Stinchcombe ou Eve Chiapello, para citar apenas alguns. Apresenta assim uma tipologia dos argumentos que acompanharam a penetração do capitalismo na esfera da arte, depois desta última se apresentar como uma "verdade utópica do homem” ou ainda um "agente de protesto contra o capitalismo". E termina com uma interessante discussão em torno da arte como um modelo para a inovação e para a divisão social do trabalho. $\mathrm{Na}$ segunda parte, Pierre-Michel Menger trata as desigualdades presentes no mundo das artes e do espectáculo, no que respeita ao sucesso e à remuneração. $\mathrm{O}$ autor analisa os critérios que legitimam as disparidades encontradas e os fundamentos não monetários para a escolha destas profissões.

Discute, ainda, os principais mecanismos responsáveis pela construção da reputação individual dos artistas e dos grupos: "A reputação é ao mesmo tempo um capital acumulável que confere ao seu detentor um poder para orientar as suas escolhas de projecto e equipa, um sinal necessário para o consumidor quando ele não pode conhecer o conteúdo da obra [...] e um elemento de identificação do qual a comunidade profissional se serve [...] para organizar os seus projectos e diminuir a incerteza dos resultados” (p. 46).
Na terceira parte, Pierre-Michel Menger debruça-se sobre os sistemas de emprego que caracterizam actualmente a actividade artística, na Europa e nos Estados Unidos. Ao utilizar estes contributos, o autor faz uma análise das transformações no mercado de trabalho contemporâneo.

A dinâmica das organizações e dos mercados artísticos remetem o autor para a análise de temas que há muito tempo fazem parte das suas investigações: a variedade de competências e talentos que são pedidos ao artista como forma de reduzir os riscos da concorrência pela inovação e da actividade desenvolvida por projecto.

Para terminar, o autor argumenta que as artes parecem surgir, ironicamente, como percursoras de formas flexíveis de emprego, de combinações múltiplas de actividades e de modalidades de exercício do trabalho, originando o que designou por "hibridação dos estatutos da actividade" artística.

O grande mérito deste último livro de Pierre-Michel Menger é desenvolver uma interessante análise sociológica e socioeconómica do trabalho artístico, aproveitando os ensinamentos de uma obra muito rica, construída ao longo dos anos que tem dedicado à investigação.

Muito estimulante para aqueles que trabalham ou começam a trabalhar nestas áreas temáticas, o trabalho de Pierre-Michel Menger revela-se um importante modelo e instrumento de análise para os mundos sociais das artes, em terreno português. Assim, quer pela pertinência do seu quadro teórico, quer pela qualidade das suas reflexões e resultados apresentados, os seus livros mais recentemente publicados são referências incontornáveis nesta área de pesquisa.

\section{Vera Borges}

